Revista Brasil. Bot., V.31, n.4, p.701-713, out.-dez. 2008

\title{
Laticíferos articulados anastomosados em espécies de Asclepiadeae (Asclepiadoideae, Apocynaceae) e suas implicações ecológicas ${ }^{1}$
}

\author{
DIEGO DEMARCO ${ }^{2,3}$ e MARILIA DE MORAES CASTRO²
}

(recebido: 25 de novembro de 2007; aceito: 29 de agosto de 2008)

\begin{abstract}
Articulated anastomosing laticifers in species of Asclepiadeae (Asclepiadoideae, Apocynaceae) and their ecological significance). Laticifers occur in all members of Apocynaceae. They are described as nonarticulated branched by most authors, but articulated laticifers have been reported to some species of this family. The present study aims to describe the laticifer ontogeny, structure, distribution, and type in vegetative organs of Fischeria stellata (Vell.) E.Fourn., Gonioanthela axillaris (Vell.) Fontella \& E.A. Schwarz, Matelea denticulata (Vahl) Fontella \& E.A. Schwarz, and Oxypetalum banksii Schult. and re-evaluate the laticifers of Asclepias curassavica L. from Atlantic rainforest, comparing the results with those of species from "cerrado" vegetation. The laticifers of these five species are articulated anastomosing, whose transverse or oblique walls dissolve rapidly and entirely. The laticifers branch through lateral anastomoses and form a continuous system throughout the adult plant. They are observed in primary tissues of stem and leaf, except in epidermis; they are also present in the secondary vascular tissue, except in the secondary xylem of A. curassavica. The ontogeny of these laticifers may explain the divergence between our data and those recorded for most species of the family. The results obtained revealed that the ontogeny, type, structure, and distribution of laticifers of the species of Asclepiadeae from "restinga", lowland humid forests, and "cerrado" vegetation are similar. The continuity of the articulated anastomosing laticifer system ensures a greater latex flow into the injured organ, releasing the laticifer exsudate simultaneously, coagulating and sealing the wounds rapidly, besides hindering the entrance of microorganisms.
\end{abstract}

Key words - articulated laticifers, Asclepiadeae, ontogeny, "restinga" and lowland humid forests, structure

RESUMO - (Laticíferos articulados anastomosados em espécies de Asclepiadeae (Asclepiadoideae, Apocynaceae) e suas implicações ecológicas). Laticíferos ocorrem em todos os representantes de Apocynaceae e são considerados não articulados ramificados pela maioria dos autores; entretanto, laticíferos articulados têm sido descritos para algumas espécies da família. O presente trabalho tem por objetivo descrever a ontogênese, estrutura, distribuição e o tipo dos laticíferos em órgãos vegetativos de Fischeria stellata (Vell.) E.Fourn., Gonioanthela axillaris (Vell.) Fontella \& E.A. Schwarz, Matelea denticulata (Vahl) Fontella \& E.A. Schwarz e Oxypetalum banksii Schult. e reavaliar os laticíferos de Asclepias curassavica L. de mata atlântica, comparando os resultados aos de espécies de cerrado. Os laticíferos das cinco espécies são articulados anastomosados, cujas paredes transversais ou oblíquas são dissolvidas rápida e integralmente. Os laticíferos ramificam-se através de anastomose lateral e formam um sistema contínuo por todos os órgãos da planta adulta. Eles são observados em todos os tecidos primários do caule e da folha, excetuando-se a epiderme, e no tecido vascular secundário, exceto no xilema secundário de A. curassavica. A ontogênese destes laticíferos pode explicar a divergência entre os nossos dados e aqueles publicados para a grande maioria das espécies desta família. Os resultados obtidos evidenciam que a ontogênese, estrutura e distribuição dos laticíferos das espécies de Asclepiadeae de floresta de restinga, floresta ombrófila densa de terras baixas e cerrado são semelhantes. A continuidade do sistema laticífero articulado anastomosado permite um maior afluxo de látex ao local injuriado, pois o conteúdo das regiões interconectadas é liberado simultaneamente, coagulando e selando os ferimentos rapidamente, além de impedir a entrada de microorganismos.

Palavras-chave - Asclepiadeae, estrutura, floresta de restinga, floresta ombrófila densa de terras baixas, laticíferos articulados, ontogênese

\section{Introdução}

Os laticíferos ocorrem em todos os representantes de Apocynaceae e foram considerados não articulados

1. Parte da tese de doutorado de Diego Demarco, Programa de Pósgraduação em Biologia Vegetal da Universidade Estadual de Campinas, Campinas.

2. Universidade Estadual de Campinas, Instituto de Biologia, Departamento de Botânica, Caixa Postal 6109, 13083-970 Campinas, SP, Brasil.

3. Autor para correspondência: diego_demarco@hotmail.com nas obras de revisão (Solereder 1908, Metcalfe \& Chalk 1950, Metcalfe 1967). Esta classificação foi criada por De Bary (1884) e este tipo de laticífero é descrito como uma única célula de crescimento autônomo intrusivo ilimitado através dos espaços intercelulares nos diversos tecidos (Mahlberg 1993). Entretanto, incongruências quanto à identificação de seu tipo e sua formação podem ser encontradas na literatura, como em Cryptostegia grandiflora R. Br. e Nerium oleander L. (Blaser 1945, Milanez 1960/1961, 1966, 1977, Mahlberg 1961, 1963); 
além disso, laticíferos articulados têm sido registrados para outras espécies da família (Wilson \& Maxam 1987, Sacchetti et al. 1999, Demarco et al. 2006).

O látex é o próprio protoplasto do laticífero (Demarco et al. 2006) e possui pequenas partículas em suspensão (Fahn 1979) compostas predominantemente por lipídios, especialmente terpenos (van Die 1955, Giordani 1996). O látex protege as plantas contra herbivoria e microorganismos, além de selar ferimentos (Farrell et al. 1991, Pickard 2008) e as linhagens de plantas latescentes têm maior diversidade que seus grupos irmãos não latescentes em diversos habitat (Farrell et al. 1991).

As características morfológicas e químicas dos laticíferos podem ser utilizadas como caráter taxonômico devido à provável origem polifilética dos articulados e não articulados (Mahlberg 1993). A presença de laticíferos articulados em quatro das cinco subfamílias de Apocynaceae corrobora a sua atual circunscrição (Demarco et al. 2006) e, em alguns casos, a composição da fração particulada do látex também pode servir como uma indicação das relações sistemáticas de espécies que são difíceis de distinguir morfologicamente, como ocorre em Plumeria (van Die 1955).

Os laticíferos estão presentes em todos os órgãos vegetativos de todas as espécies de Apocynaceae (Metcalfe \& Chalk 1950) e embora muitos sejam os trabalhos sobre esta estrutura, as divergências encontradas na literatura ressaltam a importância do estudo de sua ontogênese para a identificação do seu tipo (Demarco et al. 2006).

Laticíferos foram citados para espécies de Fischeria, Gonioanthela, Matelea e Oxypetalum (Pereira et al. 1971, Silva et al. 1975, Murphy 1986, Valente 1996), mas nunca pesquisados anatomicamente. Os laticíferos de Asclepias curassavica $\mathrm{L}$. já foram muito estudados com relação à sua estrutura, distribuição e composição do látex (Groom 1889, Arraes 1960, Giordani 1996), enquanto que apenas a distribuição dos de Oxypetalum banksii Schult. foi investigada.

Oobjetivo do presente trabalhoé descrever a ontogênese e o tipo dos laticíferos foliares e caulinares, analisar sua estrutura e distribuição em órgãos vegetativos aéreos de Fischeria stellata (Vell.) E. Fourn., Gonioanthela axillaris (Vell.) Fontella \& E.A. Schwarz, Matelea denticulata (Vahl) Fontella \& E.A. Schwarz e Oxypetalum banksii e reavaliar a ontogênese e o tipo de laticífero de Asclepias curassavica L. Através de análise comparativa, pretende-se verificar se as características morfológicas dos sistemas laticíferos das espécies de Asclepiadeae estudadas determinam comportamentos e/ou estratégias semelhantes nas formações de floresta de restinga, floresta ombrófila densa de terras baixas e cerrado (s.l.) do Estado de São Paulo.

\section{Material e métodos}

O material de estudo foi obtido no Parque Estadual da Serra do Mar - Núcleo Picinguaba no Município de Ubatuba (SP): Praia da Fazenda, estrada para a Casa de Farinha, Casa de Farinha e trilha do Noelo. As coletas foram realizadas nos meses de março, agosto, outubro, novembro e dezembro de 2005 e fevereiro de 2006. Cinco indivíduos de A. curassavica foram coletados na Casa de Farinha $\left(23^{\circ} 20^{\prime} 24,2^{\prime \prime}\right.$ S/

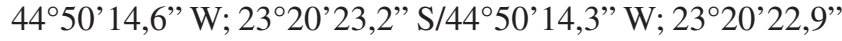

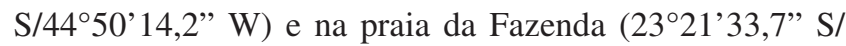
$\left.44^{\circ} 51^{\prime} 0,37^{\prime \prime} \mathrm{W}\right)$; quatro de $F$. stellata na trilha do Noelo

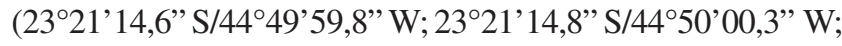
$23^{\circ} 21^{\prime} 14,0^{\prime \prime} \mathrm{S} / 44^{\circ} 50^{\prime} 00,5^{\prime \prime} \mathrm{W} ; 23^{\circ} 21^{\prime} 13,8^{\prime \prime} \mathrm{S} / 44^{\circ} 50^{\prime} 00,1^{\prime \prime} \mathrm{W}$ ); cinco de G. axillaris na Praia da Fazenda $\left(23^{\circ} 21^{\prime} 35,0^{\prime \prime} \mathrm{S} /\right.$

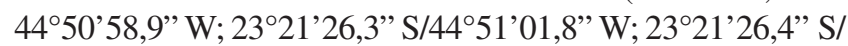
$44^{\circ} 51^{\prime} 03,7^{\prime \prime} \mathrm{W} ; 23^{\circ} 21^{\prime} 26,1^{\prime \prime} \mathrm{S} / 44^{\circ} 51^{\prime} 03,6^{\prime}$ 'W) e na estrada para a Casa de Farinha $\left(23^{\circ} 20^{\prime} 53,1^{\prime \prime}\right.$ S/44 $\left.51^{\prime} 00,9^{\prime \prime} \mathrm{W}\right)$; quatro de $M$. denticulata na estrada para a Casa de Farinha

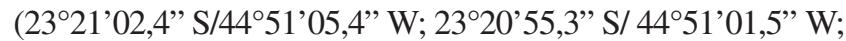
$\left.23^{\circ} 21^{\prime} 02,4^{\prime \prime} \mathrm{S} / 44^{\circ} 51^{\prime} 05,4^{\prime \prime} \mathrm{W}\right)$ e três de $O$. banksii na Praia

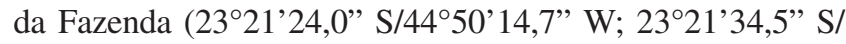
$\left.44^{\circ} 51^{\prime} 02,1^{\prime \prime} \mathrm{W} ; 23^{\circ} 21^{\prime} 34,4^{\prime \prime} \mathrm{S} / 44^{\circ} 51^{\prime} 04,3^{\prime \prime} \mathrm{W}\right)$. Materiais testemunha dos indivíduos processados estão depositados nos Herbários UEC e D. Bento Pickel (SPSF).

Ramos vegetativos de A. curassavica, $F$. stellata, $G$. axillaris, $M$. denticulata e $O$. banksii foram coletados, fixados em FAA em etanol 50\% (Johansen 1940) por 24h e em FNT (formalina neutra tamponada) em tampão fosfato de sódio pH 7,0 (Lillie 1965) por 48h e estocados em etanol 70\%.

Ápices vegetativos e entrenós em estrutura secundária foram isolados, desidratados em série butílica (álcool butílico terciário; Johansen 1940), incluídos em Paraplast e seccionados transversal e longitudinalmente em micrótomo rotativo Microm HM340E. Secções, com 10 a $18 \mu$ m de espessura, foram coradas com azul de astra e safranina (Gerlach 1984) e as lâminas montadas em resina sintética.

As fotomicrografias foram obtidas em microscópio Olympus BX 51 utilizando-se filme Kodak ProImage ASA 100 e as escalas das figuras, através de lâmina micrométrica fotografada nas mesmas condições ópticas das demais ilustrações. As mensurações dos laticíferos foram realizadas a partir das fotomicrografias e desenhos em câmara clara com a utilização de paquímetro digital.

\section{Resultados}

Os laticíferos presentes nos órgãos vegetativos de A. curassavica, $F$. stellata, G. axillaris, M. denticulata e $O$. banksii distinguem-se dos demais tecidos, devido 
ao seu calibre, conteúdo, espessura das paredes e ramificações do sistema (figuras 1-36). As cinco espécies possuem laticíferos primários, no caule e na folha (figuras 1-32), e laticíferos secundários no tecido vascular caulinar (figuras 33-36).

Ontogênese e estrutura - O laticífero diferencia-se precocemente na ontogênese dos órgãos e, enquanto a maioria dos tecidos ainda é meristemática ou está em processo de diferenciação, ele já se encontra diferenciado (figuras 1-17).

Os laticíferos das cinco espécies são articulados anastomosados. Eles são formados pela adição de células, cujas paredes transversais ou oblíquas podem ser observadas em suas porções apicais (figuras 2-4, 6-7, 9-10, 12-13, 15-17); pouco abaixo dos ápices dos laticíferos, estas paredes são dissolvidas e as células unem-se sem deixar vestígios de seus limites (figuras 4 , 10, 15-17,19, 21-22, 26, 34-35).

A primeira característica que permite distinguir a célula apical de um laticífero das meristemáticas adjacentes é a sua parede. Logo no início de sua diferenciação, a parede desta célula torna-se mais espessa que a parede das demais células (figuras 6-7, 9-10, 12, 15-17, 19).

Os sistemas laticíferos primários originam-se no início do desenvolvimento dos órgãos e já podem ser distinguidos às margens do promeristema (figuras 1, 5, $8,11,14)$. Eles são derivados de células do meristema fundamental e/ou procâmbio (figuras 1-17). Os secundários (figuras 33-36) são provenientes das iniciais fusiformes e/ou radiais do câmbio. Os laticíferos só crescem em comprimento em regiões meristemáticas por adição de novas células e alongamento celular. A anastomose lateral gera um sistema ramificado (figuras 4, 17); estas ramificações ocorrem no início do desenvolvimento dos laticíferos e são observadas principalmente nas regiões nodais, no córtex caulinar e na lâmina foliar (figuras 1 , $4-5,8,11,14,17-18,21,34)$. Alguns laticíferos possuem forma de "H" (figura 18, *), evidenciando a existência de anastomose entre dois laticíferos próximos (figura 17).

O diâmetro dos laticíferos varia de 3 a $30 \mu \mathrm{m}$ dependendo da porção analisada e do tecido em que estão presentes. Os mais calibrosos são observados na medula e no floema (figuras 27-33).

Há continuidade entre o sistema laticífero caulinar e foliar e, embora a maioria dos laticíferos medulares do caule seja contínua com os do primórdio foliar através da lacuna foliar, muitos podem ser observados atravessando o procâmbio (figuras 1,4 ) e a faixa cambial (figura 34) através da anastomose das respectivas células meristemáticas.
Após a anastomose das paredes de contato, os protoplastos das células unem-se formando um único protoplasto em toda a extensão do laticífero (figuras 21-22, 26, 34).

As células que compõem o laticífero iniciam sua atividade secretora logo após a diferenciação de suas paredes e alguns laticíferos podem ser encontrados com secreção desde sua porção apical. A secreção ocupa todo lume celular (figuras 20-22, 26-27, 30-34) e, aparentemente, as diversas vesículas de secreção (figuras 19-20, 22, 25) fundem-se ao vacúolo central, liberando o conteúdo em seu interior; com o aumento de volume do vacúolo central, os núcleos e o citoplasma ficam restritos a uma fina camada parietal.

Durante o desenvolvimento do laticífero, há lise de parte de seu citoplasma e ocorre degeneração de diversos núcleos, os quais apresentam intensa coloração; poucos estão presentes nos laticíferos maduros (figuras 24-26). Os núcleos de cada laticífero são provenientes de diferentes células e nenhum indício de fusão ou divisão nuclear foi observado. Eles possuem cromatina pouco corada e um a dois nucléolos evidentes (figuras 23-24, 26); inicialmente são esféricos (figura 23) e, com a pressão exercida pela ampliação do vacúolo, tornam-se alongados e fusiformes (figura 24). Diversos núcleos são deslocados pelo extravasamento do látex durante a coleta e são observados em grande quantidade próximos à região de secção do material (figura 26).

Os laticíferos permanecem vivos e com a secreção em seu interior (figuras 18-36). O látex é o próprio protoplasto do laticífero e apresenta aspecto leitoso e cor branca nas cinco espécies. Durante as coletas dos espécimens, notou-se que o látex é imediatamente liberado e que, em pouco tempo, coagula e sela o órgão injuriado. Não foram observados sinais de predação nos indivíduos das espécies estudadas.

Distribuição - Os laticíferos estão presentes permeando os tecidos fundamental e vascular do caule e da folha (figuras 1-36) e formam um sistema ramificado (figuras $1,5,8,11,14,21,34)$ que interconecta grande parte dos laticíferos nestes órgãos da planta adulta.

Os laticíferos primários ocorrem em maior concentração junto ao floema (figuras 27-30, 32-33) e nas regiões nodais, devido ao grande número de ramificações neste local (figuras $1,5,8,11,14$ ). Seu trajeto pode ser sinuoso ou retilíneo; normalmente, os laticíferos vasculares e medulares são retilíneos e raramente ramificados na região do entrenó (figuras 1, 4, 11, 14, 22).

Os laticíferos secundários são facilmente observados tanto no floema quanto no xilema secundários (figuras 

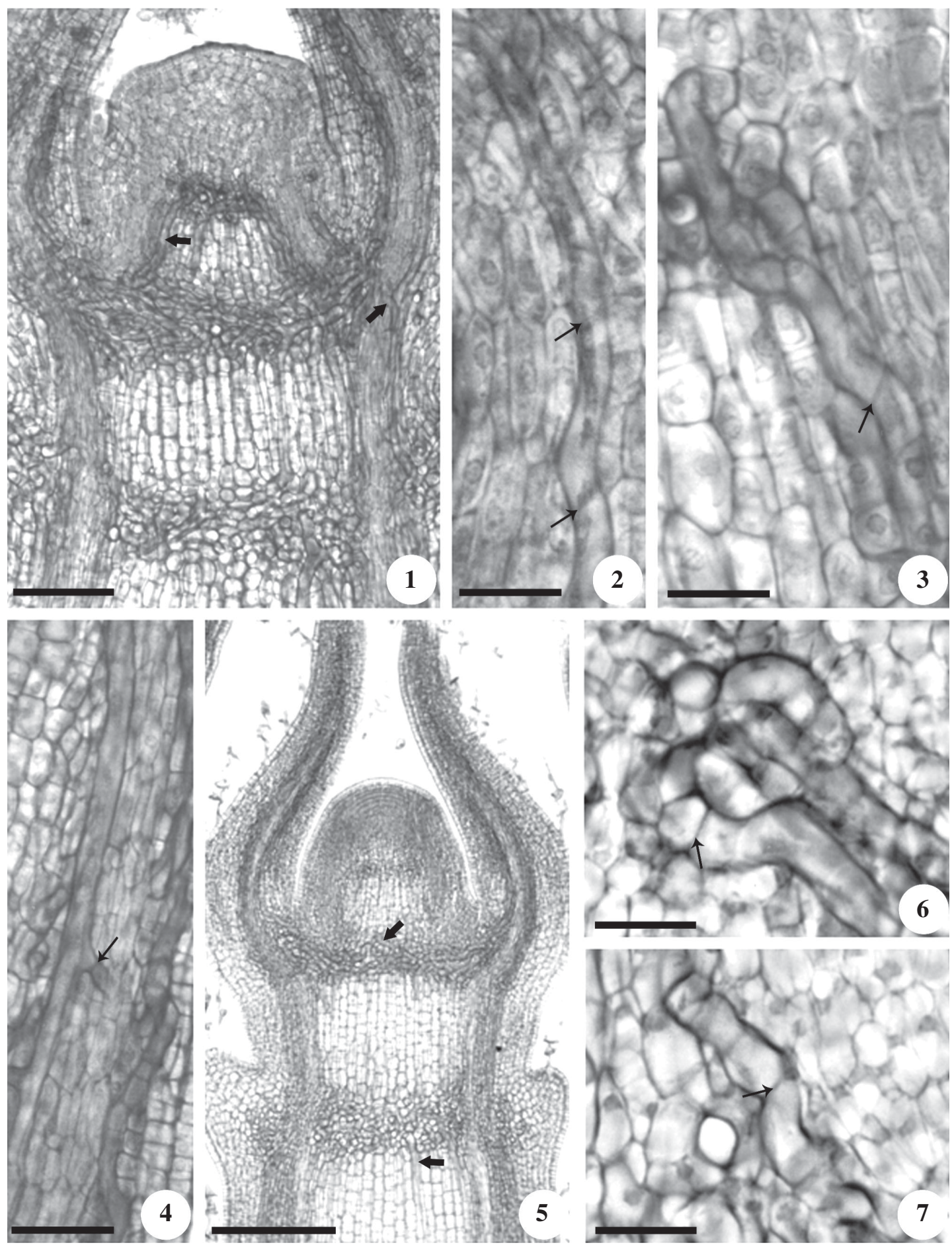

Figuras 1-7. Ontogênese dos laticíferos articulados anastomosados de Asclepias curassavica (1-4) e Fischeria stellata (5-7). 1,5. Vista geral do ápice vegetativo. 2,4,7. Primórdios foliares. 3,6. Primórdio caulinar. 4. Ramo transestelar formado por anastomose lateral. (seta larga $=$ laticífero, seta estreita $=$ parede transversal/oblíqua). Barra $=75 \mu \mathrm{m}(1), 15 \mu \mathrm{m}(2-3,6-7)$, $30 \mu \mathrm{m}(4), 150 \mu \mathrm{m}(5)$.

Figures 1-7. Articulated anastomosing laticifers ontogeny of Asclepias curassavica (1-4) and Fischeria stellata (5-7). 1,5. General view of the shoot apex. 2,4,7. Leaf primordia. 3,6. Stem primordium. 4. Transtelar branch formed by lateral anastomosis. (large arrow $=$ laticifer, thin arrow $=$ transverse/oblique wall). Bar $=75 \mu \mathrm{m}(1), 15 \mu \mathrm{m}(2-3,6-7), 30 \mu \mathrm{m}(4)$, $150 \mu \mathrm{m}$ (5). 

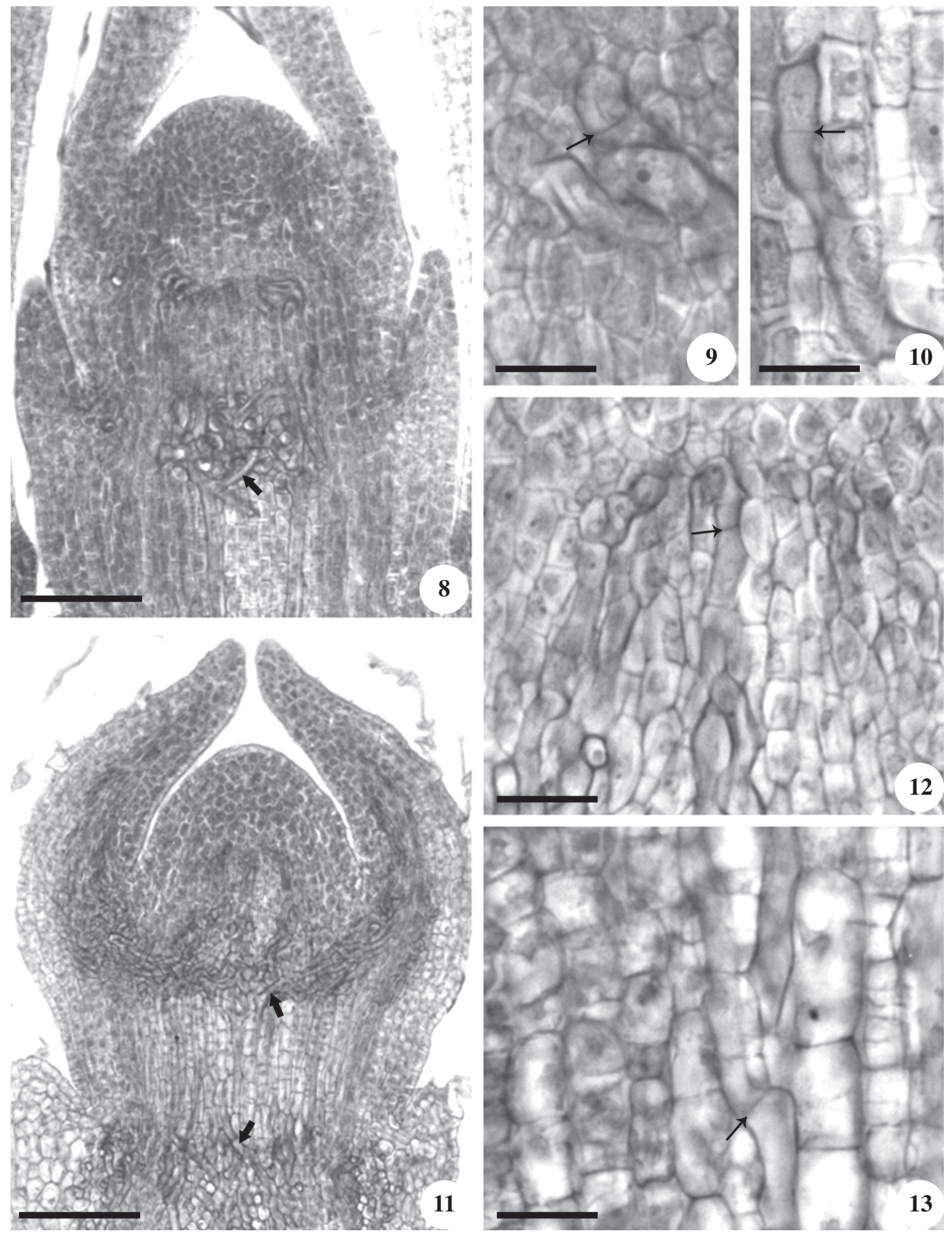

Figuras 8-13. Ontogênese dos laticíferos articulados anastomosados de Gonioanthela axillaris (8-10) e Matelea denticulata (11-13). 8,11. Vista geral do ápice vegetativo. 9. Primórdio foliar. 10,13. Caule jovem. 12. Primórdios caulinares. (seta larga $=$ laticífero, seta estreita $=$ parede transversal/oblíqua). Barra $=75 \mu \mathrm{m}(8,11), 15 \mu \mathrm{m}(9-10,12-13)$.

Figures 8-13. Articulated anastomosing laticifers ontogeny of Gonioanthela axillaris (8-10) and Matelea denticulata (11-13). 8,11 . General view of the shoot apex. 9. Leaf primordium. 10,13. Young stem. 12. Stem primordia. (large arrow $=$ laticifer, thin arrow $=$ transverse/oblique wall). Bar $=75 \mu \mathrm{m}(8,11), 15 \mu \mathrm{m}(9-10,12-13)$. 

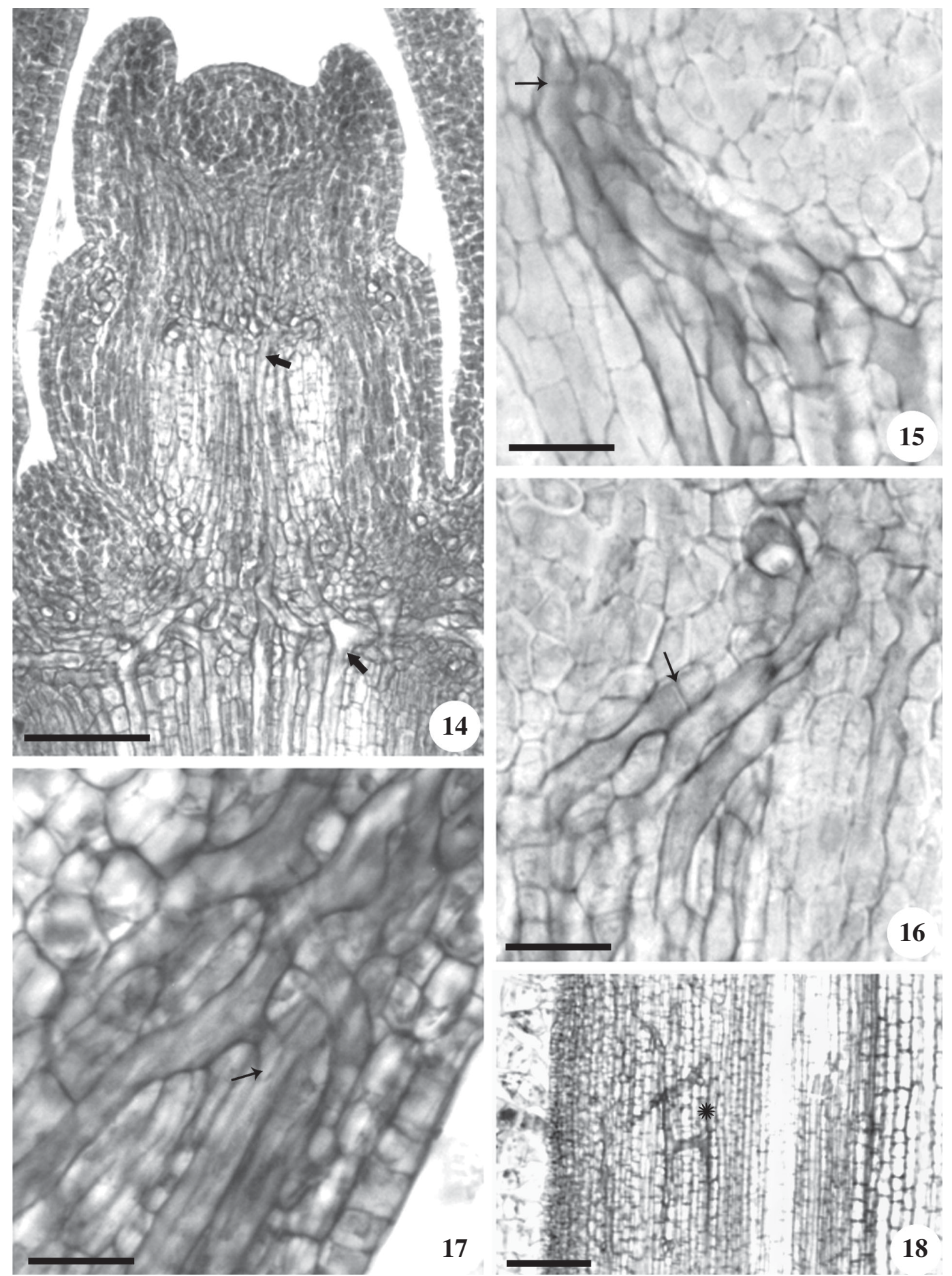

Figuras 14-18. Ontogênese e estrutura dos laticíferos articulados anastomosados. 14-16. Oxypetalum banksii. 17-18. Asclepias curassavica. 14. Vista geral do ápice vegetativo com laticíferos (seta larga). 15-16. Formação dos laticíferos na região nodal. 17. Anastomose entre laticíferos no primórdio foliar (seta). 18. Córtex caulinar. Notar laticífero em forma de "H" (*). (seta estreita $=$ parede transversal/oblíqua). Barra $=75 \mu \mathrm{m}(14), 15 \mu \mathrm{m}(15-17), 150 \mu \mathrm{m}(18)$.

Figures 14-18. Ontogeny and structure of the articulated anastomosing laticifers. 14-16. Oxypetalum banksii. 17-18. Asclepias curassavica. 14. General view of the shoot apex with laticifers (large arrow). 15-16. Differentiation of laticifers in nodal region. 17. Anastomosis between laticifers in leaf primordium (arrow). 18. Stem cortex. Note H-shaped laticifer $(*)$. (thin arrow $=$ transverse/oblique wall). $\mathrm{Bar}=75 \mu \mathrm{m}(14), 15 \mu \mathrm{m}(15-17), 150 \mu \mathrm{m}(18)$. 
33-36). Eles ocorrem principalmente no sistema axial (figuras 33-35), mas são comuns no sistema radial de O. banksii (figura 36). As cinco espécies possuem laticíferos secundários no floema e xilema, exceto $A$. curassavica que não os possui no xilema secundário.

\section{Discussão}

Diferentes classificações e terminologias foram sugeridas ao longo do estudo dos laticíferos (De Bary 1884, Chauveaud 1891, Solereder 1908, Metcalfe \& Chalk 1950, Metcalfe 1967, Milanez 1978, Fahn 1979, Mahlberg 1993), mas a classificação mais aceita é a de De Bary (1884), que propôs dois tipos de laticíferos: os articulados e os não articulados. Esta classificação é baseada na sua ontogênese e alguns autores discordaram quanto à maneira de crescimento dos laticíferos não articulados.

Os laticíferos de A. curassavica, F. stellata, $G$. axillaris, $M$. denticulata e $O$. banksii são articulados, mas, de modo geral, os laticíferos da grande maioria das espécies de Apocynaceae, Euphorbiaceae e Moraceae são considerados não articulados, que se alongam por crescimento apical intrusivo através dos espaços intercelulares nos diversos tecidos da planta (Chauveaud 1891, Metcalfe 1967, Mahlberg 1993). Entretanto, Milanez (1978) relatou a origem destes mesmos laticíferos por fusão rápida e completa de células. Embora Milanez tenha identificado estes laticíferos como contínuos, eles deveriam ser classificados como articulados anastomosados com base em sua ontogênese, pois as paredes transversais dissolvem-se rapidamente sem deixar vestígios, à semelhança do que ocorre em Aspidosperma australe Müll. Arg. e Blepharodon bicuspidatum E. Fourn (Demarco et al. 2006).

Os laticíferos das cinco espécies estudadas não têm crescimento intrusivo e o ápice agudo, observado muitas vezes, é resultado de uma secção oblíqua à célula apical. Wilson \& Mahlberg (1977) investigaram a diferenciação de laticíferos em embrióides e ápices caulinares induzidos em cultura de tecidos de Asclepias syriaca L., mas formação de laticíferos foi encontrada apenas nos meristemas caulinares derivados da superfície do calo, sempre em meio aos meristemas primários. Dhir et al. (1984) registraram a diferenciação de laticíferos em calos de 40 dias obtidos de ramos jovens de Calotropis procera (Ait.) R. Br.; embora tenham considerado os laticíferos como células laticíferas (não articulados) ramificadas, observaram dissolução de paredes terminais em culturas com seis semanas.

Laticíferos atravessando o procâmbio e a faixa cambial, sem causar qualquer deformidade nestas células intimamente relacionadas, são comuns e ocorrem nas espécies analisadas. Ramos transestelares também foram registrados em Cryptostegia grandiflora (Blaser 1945, Milanez 1960/1961, 1966), Nerium oleander (Mahlberg 1963) e Blepharodon bicuspidatum (Demarco et al. 2006). Segundo Blaser (1945), os laticíferos não atravessaram o câmbio, mas foram envolvidos por este; entretanto, não soube explicar como o crescimento secundário não rompeu estes laticíferos. Por outro lado, no presente estudo, este fato é facilmente explicado pela observação de anastomose do laticífero com células derivadas do procâmbio ou câmbio, assim como mencionado para C. grandiflora (Milanez 1960/1961, 1966) e B. bicuspidatum (Demarco et al. 2006).

Embora a grande maioria dos laticíferos das espécies de Apocynaceae seja descrita como do tipo não articulado (Groom 1889, Chauveaud 1891, Solereder 1908, Mahlberg 1959, 1963, 1993, Arraes 1960, Metcalfe 1967, Wilson et al. 1976, Wilson \& Mahlberg 1977, Giordani 1996, Allen \& Nessler 1984, Dhir et al. 1984, Murugan \& Inamdar 1987, Appezzato-da-Glória \& Estelita 1997, Serpe et al. 2001), a análise das terminações dos laticíferos de A. curassavica, F. stellata, G. axillaris, $M$. denticulata e $O$. banksii evidenciou que eles são articulados anastomosados, cujas paredes transversais ou oblíquas das células que o constituem dissolvem-se rapida e integralmente; não sendo encontradas, logo abaixo de seu ápice. Estes registros discordam da interpretação geral dos laticíferos atribuída à família (Chauveaud 1891, Solereder 1908, Metcalfe 1967, Mahlberg 1993), incluindo os gêneros Asclepias e Oxypetalum (Chauveaud 1891, Solereder 1908, Wilson et al. 1976, Wilson \& Mahlberg 1977, Serpe et al. 2001). Divergência semelhante ocorre em relação aos laticíferos articulados de Asclepias curassavica, Aspidosperma australe, Cryptostegia grandiflora, Nerium oleander, Stapelia bella A. Berger e Vinca sardoa (Stearn) Pign. (Groom 1889, Blaser 1945, Arraes 1960, Milanez 1960/ 1961, 1966, 1977, Mahlberg 1961, 1963, Wilson \& Maxam 1987, Giordani 1996, Sacchetti et al. 1999, Demarco et al. 2006). A rápida dissolução das paredes transversais ou oblíquas observada nos laticíferos das espécies analisadas dificulta a sua identificação e pode explicar a ocorrência de imprecisões na sua descrição em espécies de Apocynaceae. A presença de laticíferos articulados em espécies desta família pode ser mais comum do que se tem descrito na literatura; recomenda-se evitar o uso de órgãos adultos para a sua tipificação.

Nas cinco espécies estudadas, os laticíferos são constantemente formados, não havendo um número prédeterminado de células iniciais laticíferas, como proposto 


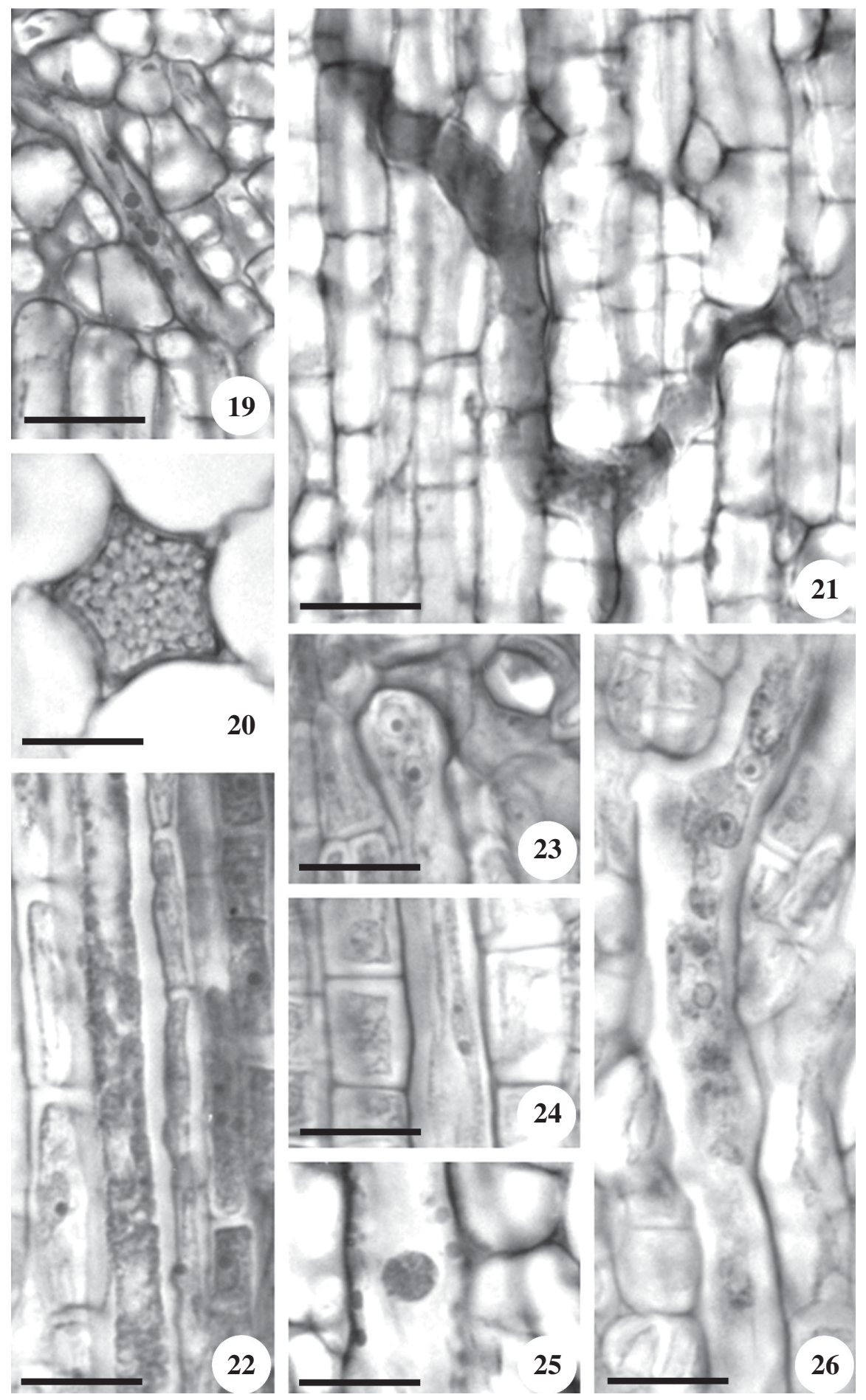

Figuras 19-26. Estrutura dos laticíferos articulados anastomosados de Asclepias curassavica (19), Fischeria stellata (20-21,25) e Gonioanthela axillaris (22-24,26). 19-20. Vesículas no látex. 21-22,24-26. Laticíferos maduros. 23. Laticífero jovem com núcleos esféricos. 24. Núcleo alongado e fusiforme. 25. Núcleo em degeneração. 26. Núcleos próximos à região de secção do material coletado. Barra $=30 \mu \mathrm{m}(19), 15 \mu \mathrm{m}(20-26)$.

Figures 19-26. Articulated anastomosing laticifers structure of Asclepias curassavica (19), Fischeria stellata (20-21,25), and Gonioanthela axillaris $(22-24,26)$. 19-20. Vesicles in the latex. 21-22,24-26. Mature laticifers. 23. Young laticifer with spherical nuclei. 24. Elongate and fusiform nucleus. 25. Degenerating nucleus. 26. Nuclei near the section region of the sample. $\mathrm{Bar}=30 \mu \mathrm{m}$ (19), $15 \mu \mathrm{m}(20-26)$. 

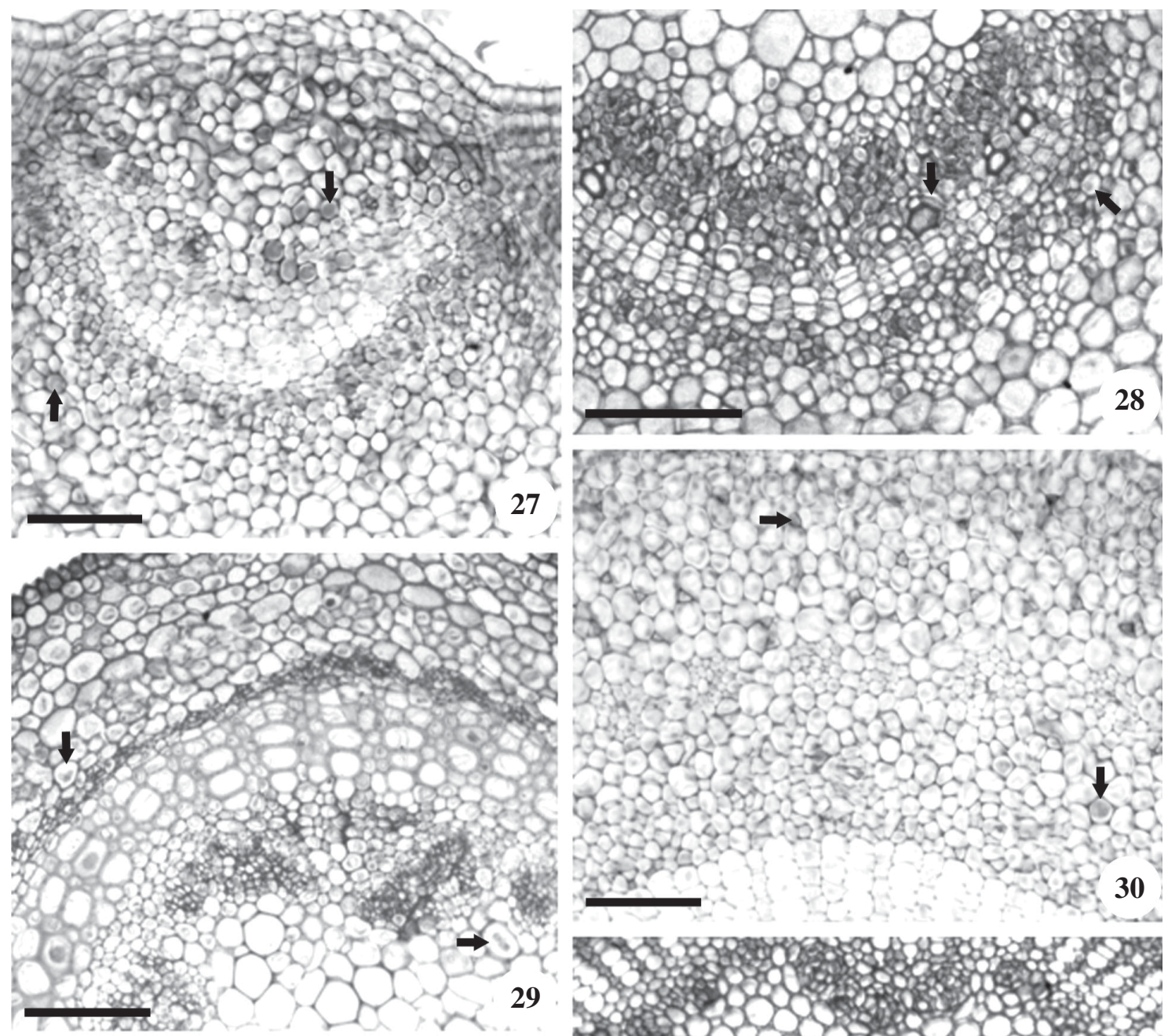

29
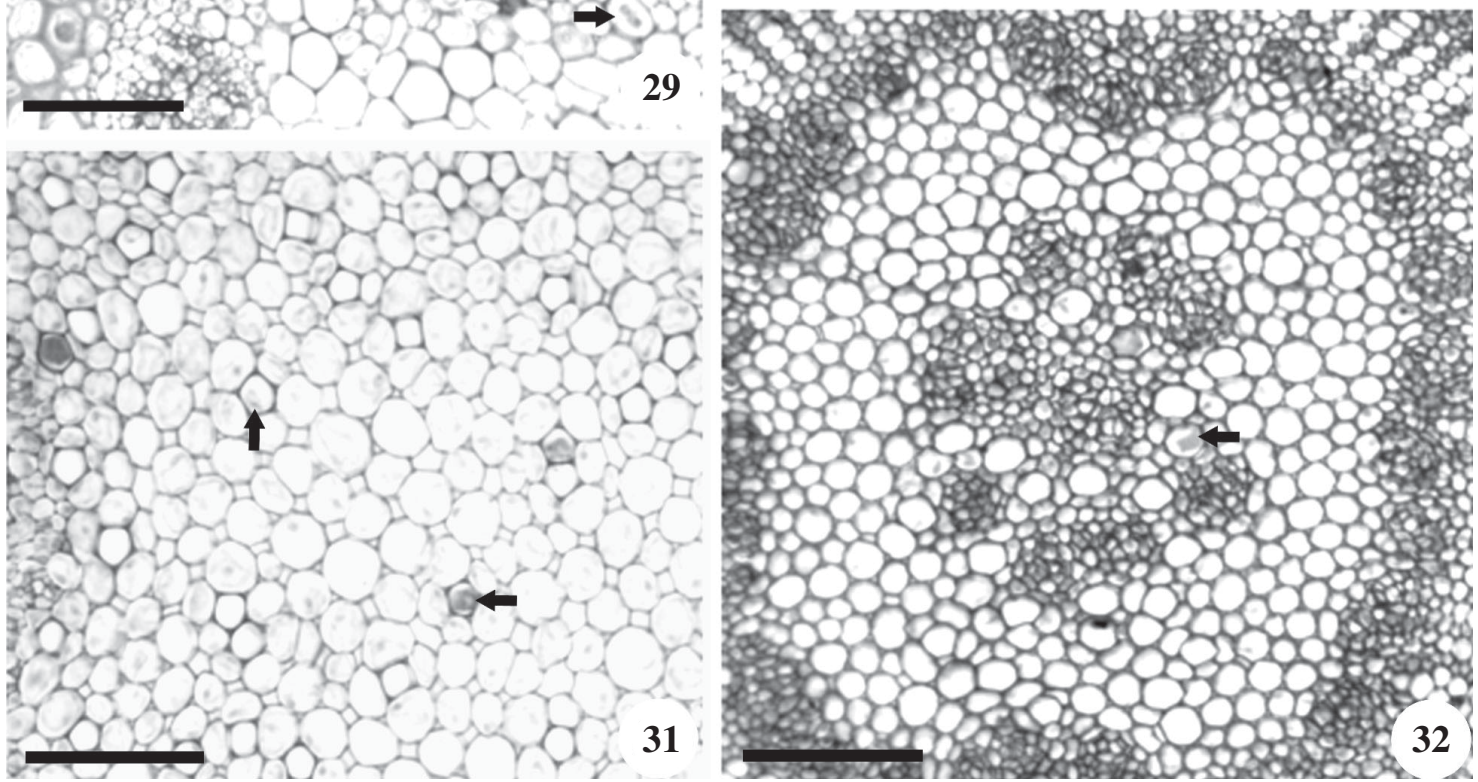

Figuras 27-32. Distribuição dos laticíferos articulados anastomosados primários em Fischeria stellata (27, 30-31), Matelea denticulata (28), Gonioanthela axillaris (29) e Oxypetalum banksii (32). 27-28. Folha. 29-32. Caule. 32. Laticíferos junto aos cordões medulares de floema. (seta $=$ laticífero). Barra $=50 \mu \mathrm{m}(27,30), 75 \mu \mathrm{m}(28-29,31-32)$.

Figures 27-32. Primary articulated anastomosing laticifers distribution in Fischeria stellata (27, 30-31), Matelea denticulata (28), Gonioanthela axillaris (29), and Oxypetalum banksii (32). 27-28. Leaf. 29-32. Stem. 32. Laticifers near medullary phloem strands. $($ arrow $=$ laticifer $)$. Bar $=50 \mu \mathrm{m}(27,30), 75 \mu \mathrm{m}(28-29,31-32)$. 

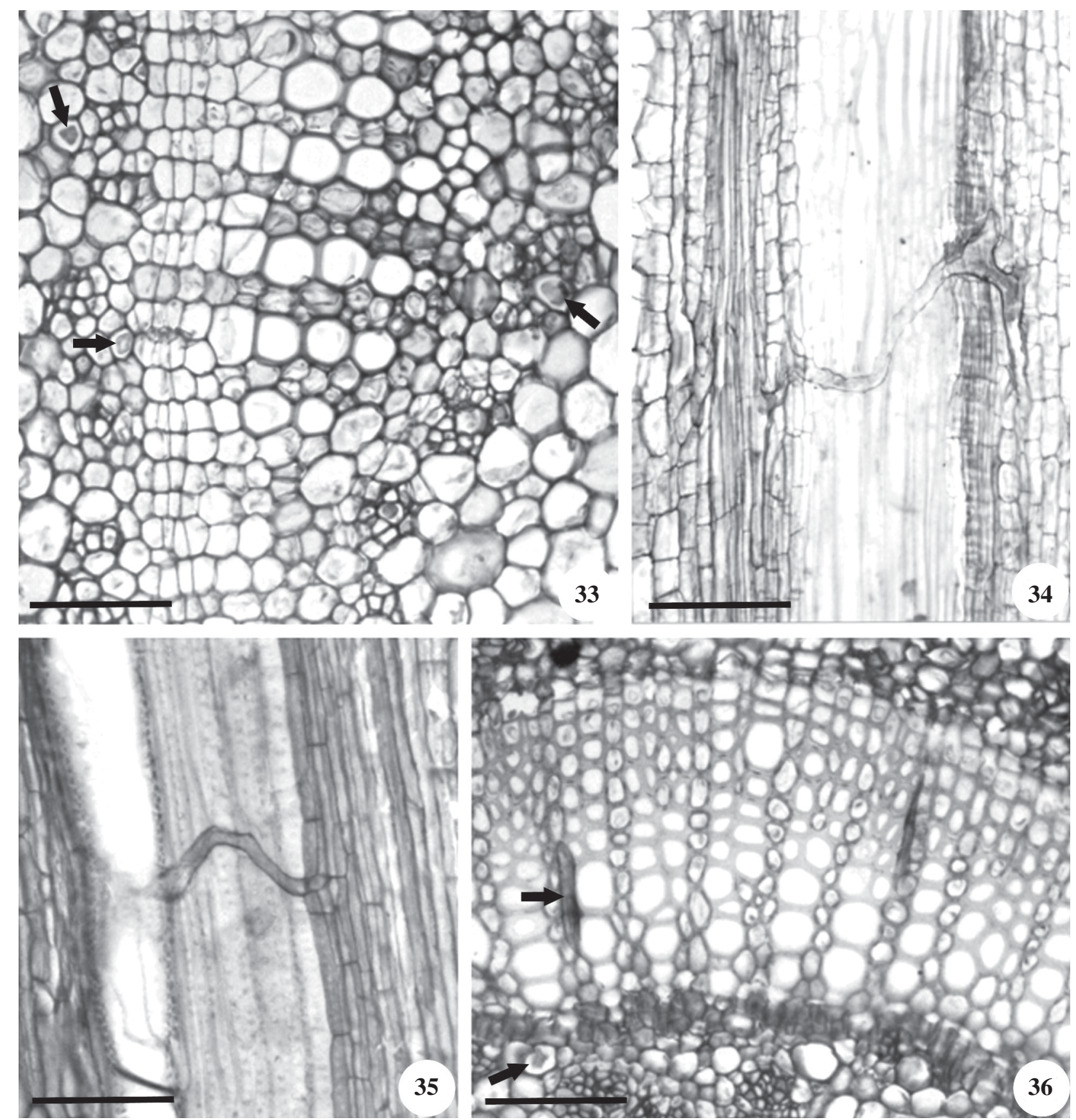

Figuras 33-36. Distribuição dos laticíferos articulados anastomosados secundários no caule de Asclepias curassavica (33), Fischeria stellata (34), Gonioanthela axillaris (35) e Oxypetalum banksii (36). 33. Laticíferos apenas no floema. 34. Laticífero no floema e xilema, atravessando a faixa cambial. 35-36. Laticíferos no xilema secundário. (seta = laticífero). Barra $=75 \mu \mathrm{m}$ $(33,35-36), 150 \mu \mathrm{m}(34)$.

Figures 33-36. Distribution of the secondary articulated anastomosing laticifers in stem of Asclepias curassavica (33), Fischeria stellata (34), Gonioanthela axillaris (35), and Oxypetalum banksii (36). 33. Laticifers only in phloem. 34. Laticifer in phloem and xylem, crossing the cambial zone. 35-36. Laticifers in secondary xylem. (arrow $=$ laticifer $).$ Bar $=75 \mu \mathrm{m}(33$, 35-36), $150 \mu \mathrm{m}$ (34). 
inicialmente para Nerium oleander (Mahlberg 1961) e, posteriormente, refutado por Milanez (1977). As anastomoses ocorrem nas regiões meristemáticas próximo aos seus ápices e os laticíferos ramificam-se por fusão lateral de outras células do meristema fundamental, procâmbio ou câmbio. A constante adição de novas células e conseqüente alongamento faz com que os laticíferos cresçam em comprimento. Fusões laterais geram ramificações, formando um sistema que interconecta a maior parte dos laticíferos da planta adulta. Laticíferos são continuamente produzidos no ápice caulinar de Vallaris solanacea (Roth) Kuntze. (Murugan \& Inamdar 1987), nos tecidos primário e secundário de Mandevilla illustris (Vell.) Woodson e M. pohliana (Stadelm.) A.H. Gentry (sob M. velutina (Mart. ex Stadelm.) Woodson; Appezzatoda-Glória \& Estelita 1997), no sistema axial do floema secundário e radial do floema e xilema secundários de Cryptostegia grandiflora (Milanez 1966) e no caule e na folha de Aspidosperma australe e Blepharodon bicuspidatum (Demarco et al. 2006).

As ramificações do sistema laticífero ocorrem em maior quantidade nas regiões nodais, no córtex caulinar e na lâmina foliar. O diâmetro dos laticíferos pode variar bastante em um mesmo órgão; os mais calibrosos são sempre os floemáticos e medulares.

As paredes dos laticíferos são exclusivamente primárias, mas sua espessura permite distinguir os laticíferos das demais células adjacentes desde sua porção apical em meio aos meristemas primários. Segundo Fahn (1979), elas podem ser tão finas quanto as paredes das células parenquimáticas ou mais espessas, são muito hidratadas e contêm uma grande proporção de substâncias pécticas e hemiceluloses. As paredes dos laticíferos têm composição diferente das paredes das demais células, que também pode variar ao longo de seu desenvolvimento (Serpe et al. 2001, Demarco et al. 2006). Algumas enzimas relacionadas com a degradação da parede celular já foram identificadas no látex. Em Asclepias syriaca, pectinase foi associada ao afrouxamento da parede celular, aumentando a sua plasticidade, e degradação das substâncias pécticas da lamela média, facilitando o crescimento intrusivo do laticífero entre as outras células (Wilson et al. 1976). Em Nerium oleander, atividade pectinase foi localizada no vacúolo e em menor quantidade nas paredes do laticífero e das células adjacentes e na lamela média, sendo associada ao crescimento intrusivo dos laticíferos (Allen \& Nessler 1984). Entretanto, esta atividade enzimática pode estar relacionada à degradação das paredes transversais dos laticíferos articulados, como ocorre em Papaver somniferum L. (Nessler \& Mahlberg 1981), e a maior presença da enzima no vacúolo provavelmente se deva ao produto da reação de lise parcial da parede que é translocado para o vacúolo por vesículas formadas a partir da membrana plasmática (Giordani 1980).

O látex é observado desde a porção mais jovem do laticífero, sendo considerado o seu protoplasto (Demarco et al. 2006). Vesículas com secreção ocorrem em todos os laticíferos jovens e aparentemente fundem-se ao vacúolo central, transferindo o conteúdo para o seu interior e fazendo com que este aumente em volume, restringindo os núcleos e o citoplasma a uma fina camada parietal.

Os laticíferos presentes nas cinco espécies estudadas são multinucleados, assim como nas demais espécies de Apocynaceae (Mahlberg 1959, 1993, Milanez 1960/1961, 1977, Demarco et al. 2006). Eles foram considerados estruturas cenocíticas por Mahlberg $(1959,1993)$, mas poucos pesquisadores detectaram a ocorrência de divisão nuclear (Mahlberg 1993). O protoplasto multinucleado das Asclepiadeae analisadas é resultante da fusão de células que são constantemente adicionadas ao sistema laticífero. Os núcleos inicialmente são esféricos e, com o aumento de volume do vacúolo, são comprimidos e tornam-se alongados e fusiformes. Parte dos núcleos degenera durante o desenvolvimento dos laticíferos e poucos são encontrados nos laticíferos maduros. Núcleos alongados e fusiformes foram registrados também em C. grandiflora e N. oleander (Mahlberg 1959, Milanez 1960/1961). Mahlberg (1959) sugeriu a cariocinese como um dos processos que permite o crescimento dos laticíferos, como uma estrutura cenocítica; entretanto, só observou divisões nucleares na região meristemática do ápice caulinar, não havendo qualquer divisão nos ápices dos ramos dos laticíferos nem em tecidos em maturação ou maduros.

Os laticíferos primários são encontrados em todas as regiões dos tecidos fundamental e vascular do caule e da folha das espécies estudadas, assim como nos demais membros da família (Groom 1889, Solereder 1908, Blaser 1945, Metcalfe \& Chalk 1950, Arraes 1960, Milanez 1960/1961, 1966, 1977, Mahlberg 1963, Pereira et al. 1971, Silva et al. 1975, Murugan \& Inamdar 1987, Valente 1996, Appezzato-da-Glória \& Estelita 1997, Sacchetti et al. 1999, Demarco et al. 2006). A única exceção é Aspidosperma australe, que não possui laticíferos medulares (Demarco et al. 2006). Os laticíferos também estão presentes no tecido vascular secundário das cinco espécies analisadas, estando ausentes apenas no xilema secundário de $A$. curassavica. Eles ocorrem nos sistemas axial e radial, mas são mais comuns no axial de A. curassavica, F. stellata, G. axillaris e $M$. denticulata, e no radial de $O$. banksii. Laticíferos já 
foram registrados em tecidos vasculares secundários de Mandevilla illustris, M. velutina (hoje M. pohliana) e Matelea maritima subsp. ganglinosa (Vell.) Fontella (Valente 1996, Appezzato-da-Glória \& Estelita 1997) e especialmente nos raios secundários de diversos gêneros de Apocynaceae (Solereder 1908, Blaser 1945, Metcalfe \& Chalk 1950, Milanez 1966).

A ontogênese e o tipo de laticífero encontrados nas espécies estudadas de Asclepiadeae são semelhantes e não variam com o tipo de vegetação. As cinco espécies de floresta de restinga e floresta ombrófila densa de terras baixas investigadas apresentam o mesmo tipo de formação dos laticíferos de B. bicuspidatum (Demarco et al. 2006), que ocorre no cerrado. A continuidade deste sistema secretor gerada pela dissolução das paredes transversais ou oblíquas e pela anastomose lateral entre diferentes laticíferos faz com que haja um maior afluxo de látex no local seccionado ou injuriado, pois o látex de grande parte das regiões interconectadas do sistema é liberado simultaneamente, o que não ocorre em plantas cujos laticíferos são articulados não anastomosados.

O látex das cinco espécies é branco leitoso, como observado também em órgãos aéreos de espécies de cerrado (Appezzato-da-Glória \& Estelita 1997, Demarco et al. 2006), mas látex avermelhado, amarelado e esverdeado já foram registrados para a família (Solereder 1908, Appezzato-da-Glória \& Estelita 1997). Sua função é proteger a planta contra herbívoros, microorganismos e selar ferimentos (Farrell et al. 1991, Demarco et al. 2006, Pickard 2008). As observações de campo confirmam estas funções, não tendo sido observado qualquer sinal de predação nos indivíduos das espécies estudadas. Durante as coletas, a sua rápida coagulação também demonstra a eficiência desta secreção em selar ferimentos, impedindo a entrada de microorganismos. Farrell et al. (1991) consideraram a presença de laticíferos como uma síndrome de defesa que propiciou uma maior diversidade das linhagens que os possuem em relação aos seus grupos irmãos.

As semelhanças quanto à ontogênese, estrutura e distribuição dos laticíferos das espécies de Asclepiadeae estudadas indicam que as características desta estrutura estão relacionadas filogeneticamente e correspondem a um mesmo comportamento e/ou estratégia de defesa nas diferentes formações vegetacionais.

Agradecimentos - Os autores agradecem à Fundação de Amparo à Pesquisa do Estado de São Paulo (Fapesp) pela bolsa de doutorado (proc. $n^{\circ}$ 04/09729-4) concedida e pelo financiamento no âmbito do Projeto Temático Gradiente Funcional (proc. no 03/12595-7), que faz parte do Programa
Biota/Fapesp - O Instituto Virtual da Biodiversidade (www.biota.org.br). Autorização Cotec/IF 41.065/2005 e autorização Ibama/CGEN 093/2005.

\section{Referências bibliográficas}

ALLEN, R.D. \& NESSLER, C.L. 1984. Cytochemical localization of pectinase activity in laticifers of Nerium oleander L. Protoplasma 119:74-78.

APPEZZATO-DA-GLÓRIA, B. \& ESTELITA, M.E.M. 1997. Laticifers systems in Mandevilla illustris and M. velutina Apocynaceae. Acta Societatis Botanicorum Poloniae 66:301-306.

ARRAES, M.A.B. 1960. Contribuição ao conhecimento de Asclepias curassavica L. Tese de doutorado, Faculdade de Farmácia e Odontologia da Universidade do Ceará, Fortaleza.

BLASER, H.W. 1945. Anatomy of Cryptostegia grandiflora with special reference to the latex system. American Journal of Botany 32:135-141.

CHAUVEAUD, L.G. 1891. Recherches embryogèniques sur l'appareil laticifère des Euphorbiacèes, Apocynées et Asclépiadées. Annales des Sciences Naturelles. Botanique et Biologie Végétale (ser. 7) 14:1-161.

DE BARY, A. 1884. Comparative anatomy of the vegetative organs of the phanerogams and ferns. English translation by F.O. Bower and D.H. Scott, Clarendon Press, Oxford.

DEMARCO, D., KINOSHITA, L.S. \& CASTRO, M. de M. 2006. Laticíferos articulados anastomosados - novos registros para Apocynaceae. Revista Brasileira de Botânica 29:133-144.

DHIR, S.K., SHEKHAWAT, N.S., PUROHIT, S.D. \& ARYA, H.C. 1984. Development of laticifer cells in callus cultures of Calotropis procera (Ait.) R.Br. Plant Cell Reports 3:206-209.

FAHN, A. 1979. Secretory tissues in plants. Academic Press, London.

FARRELL, B.D., DUSSOURD, D.E. \& MITTER, C. 1991. Escalation of plant defense: do latex/resin canals spur plant diversification? American Naturalist 138:881900.

GERLACH, D. 1984. Botanische Mikrotechnik: Eine Einführung. $3^{\text {rd }}$ ed., Georg Thieme, Stuttgart.

GIORDANI, R. 1980. Dislocation du plasmalemme et libération de vésicules pariétales lors de la dégradation des parois terminales durant la différenciation des laticifères articulés. Biologie Cellulaire 38:231-236.

GIORDANI, R. 1996. Les lipids du latex chez Asclepias curassavica et Lactuca sativa: nature, origine, localisation subcellulaire et rôle. Oleagineux Corps Gras Lipides 3:89-94.

GROOM, P. 1889. On the function of laticiferous tubes. Annals of Botany 3:157-169.

JOHANSEN, D.A. 1940. Plant microtechnique. McGrawHill, New York. 
LILLIE, R.D. 1965. Histopathologic technic and practical histochemistry. $3^{\text {rd }}$ ed., McGraw-Hill, New York.

MAHLBERG, P.G. 1959. Kariokinesis in the non-articulated laticifers of Nerium oleander L. Phytomorphology 9:110-118.

MAHLBERG, P.G. 1961. Embriogeny and histogenesis in Nerium oleander L.: II. Origin and development of the non-articulated laticifers. American Journal of Botany 48:90-99.

MAHLBERG, P.G. 1963. Development of nonarticulated laticifer in seedling axis of Nerium oleander. Botanical Gazette 124:224-231.

MAHLBERG, P.G. 1993. Laticifers: an historical perspective. The Botanical Review 59:1-23.

METCALFE, C.R. 1967. Distribution of latex in the plant kingdom. Economic Botany 21:115-127.

METCALFE, C.R. \& CHALK, L. 1950. Anatomy of the dicotyledons: leaves, stem and wood in relation to taxonomy with notes on economic uses. Clarendon Press, Oxford.

MILANEZ, F.R. 1960/1961. Contribuição ao conhecimento anatômico de Cryptostegia grandiflora - II. Sobre os laticíferos da estrutura primária (Asclepiaceae). Rodriguésia 35/36:99-128.

MILANEZ, F.R. 1966. Contribuição ao conhecimento anatômico de Cryptostegia grandiflora - III. Nota sobre a estrutura secundária. Rodriguésia 25:335-350.

MILANEZ, F.R. 1977. Ontogênese dos laticíferos contínuos de Neridium (Nerium) oleander L. Trabalhos do XXVI Congresso Nacional de Botânica, Rio de Janeiro 1975:343-379.

MILANEZ, F.R. 1978. Ontogênese dos laticíferos contínuos. Arquivos do Jardim Botânico do Rio de Janeiro 23:47114.

MURPHY, H. 1986. A revision of the genus Fischeria (Asclepiadaceae). Systematic Botany 11:229-241.

MURUGAN, V. \& INAMDAR, J.A. 1987. Studies in the laticifers of Vallaris solanacea (Roth) O. Ktze. Phytomorphology 37:209-214.

NESSLER, C.L. \& MAHLBERG, P.G. 1981. Cytochemical localization of cellulase activity in articulated, anastomosing laticifers of Papaver somniferum L. (Papaveraceae). American Journal of Botany 68:730732 .
PEREIRA, J.F., VALENTE, M. da C. \& ALENCASTRO, F.M.M.R. de. 1971. Contribuição ao estudo das Asclepiadaceae brasileiras. V. Estudo taxonômico e anatômico de Oxypetalum banksii Roem. et Schult. Rodriguésia 26:261-281.

PICKARD, W.F. 2008. Laticifers and secretory ducts: two other tube systems in plants. New Phytologist 177:877-888.

SACCHETTI, G., BALLERO, M., SERAFINI, M., ROMAGNOLI, C., BRUNI, A. \& POLI, F. 1999. Laticifer tissue distribution and alkaloid location in Vinca sardoa (Stearn) Pign. (Apocynaceae), an endemic plant of Sardinia (Italy). Phyton (Annales Rei Botanicae) 39: 265-275.

SERPE, M.D., MUIR, A.J. \& KEIDEL, A.M. 2001. Localization of cell wall polysaccharides in nonarticulated laticifers of Asclepias speciosa Torr. Protoplasma 216:215-226.

SILVA, N.M.F., VALENTE, M. da C., ALENCASTRO, F.M.M.R. de, PEREIRA, J.F. \& SUCRE, B.D. 1975. Contribuição ao estudo das Asclepiadaceae brasileiras. X. Estudos taxonômico e anatômico de: Gonioanthela odorata (Decne.) Malme e Gonioanthela hilariana (Fourn.) Malme. Revista Brasileira de Biologia 35:745756.

SOLEREDER, H. 1908. Systematic anatomy of the dicotyledons. English translation by L.A. Boodle and F.E. Fritsch, Clarendon Press, Oxford.

VALENTE, M.C. 1996. Matelea maritima subsp. ganglinosa (Vell.) Font. - Anatomia vegetal (Asclepiadaceae). Arquivos do Jardim Botânico do Rio de Janeiro 34:145176.

VAN DIE, J. 1955. A comparative study of the particle fractions from Apocynaceae latices. Annales Bogorienses 2:1-124.

WILSON, K.J. \& MAHLBERG, P.G. 1977. Investigation of laticifer differentiation in tissue cultures derived from Asclepias syriaca L. Annals of Botany 41:1049-1054.

WILSON, K.J. \& MAXAM, T.E. 1987. Ultrastructure of articulated laticifers in Stapelia bella (Asclepiadaceae). American Journal of Botany 74:628-628.

WILSON, K.J., NESSLER, C.L. \& MAHLBERG, P.G. 1976. Pectinase in Asclepias latex and its possible role in laticifer growth and development. American Journal of Botany 63:1140-1144. 